\title{
Integration of two-stage thermochemical treatment and chemical leaching for extraction of advanced biochar and high value critical raw materials from sewage sludge
}

\author{
Andre Salimbeni ${ }^{1}$, Andrea Maria Rizzo $^{1}$, David Chiaramonti ${ }^{1,2,3^{*}}$ \\ ${ }^{I}$ Renewable Energy COnsortium for R\&D (RE-CORD) Viale J. F. Kennedy, 182, 50038 Scarperia e San Piero, Italy \\ 2 "Galileo Ferraris" Energy Department, Polytechnic of Turin, Corso Duca degli Abruzzi 24, I-10129, Turin, Italy \\ ${ }^{3}$ Department of Industrial Engineering, University of Florence Viale Morgagni 50, 50134 Florence, Italy
}

\begin{abstract}
The proposed study aims at assessing the reliability of a new sludge conversion technology, based on integrating thermochemical treatment, with a chemical leaching stage for producing high quality biochar and valuable liquid with high concentration of phosphorus and other critical elements. The concept is based on the fact that sludge ash usually contains about $25 \%$ of $\mathrm{CaO}, 20 \%$ of $\mathrm{P}_{2} \mathrm{O}_{5}$, and about $25-30 \%$ of $\mathrm{SiO}_{2}$. With the removal of these elements, ash content is drastically reduced. The study is thus composed of two phases: (1) assessment of sludge thermochemical conversion routes, and (2) chemical leaching produced biochar. In the first phase, three thermochemical routes are investigated: HTC of fresh sludge at $80 \%$ moisture, slow pyrolysis of dry sludge, slow pyrolysis of HTC solid (hydrochar). In the second phase, the solid obtained by slow pyrolysis (biochar) is upgraded through leaching treatment to extract inorganic valuable elements: $\mathrm{P}, \mathrm{Mg}, \mathrm{K}$. The first phase of the study demonstrated that processing dry sludge in slow pyrolysis at $450^{\circ} \mathrm{C}$ allows to obtain a low volatile carbonaceous product with characteristics similar to a thermal coal. Second phase demonstrated that, after acid leaching process using $\mathrm{HNO}_{3}$, ash content in biochar decreased from $41.63 \%$ to $16.67 \%$. This method also demonstrated to be a valid solution to extract more than $90 \%$ of $\mathrm{P}, \mathrm{K}$, and $\mathrm{Mg}$ contained in the solid, making these elements available for being recycled in agriculture and other industrial uses. At the same time, the increase of the biochar $\mathrm{C}$ content and calorific value makes it a valid substitute of fossil coals.
\end{abstract}

\section{Introduction}

Currently sewage sludge (SL), the by-product of urban wastewater treatment processes, is generated in significant quantities worldwide. In Europe alone, around 13 million tons of dry sludge are produced annually. So far, SL has been traditionally used in agriculture, incinerated, or disposed in landfills. However, besides its valuable agronomic properties (e.g., supply of phosphorus, organic carbon, and nitrogen), SL is often contaminated with heavy metals, microorganisms, and a range of hazardous organic substances, which can pose a threat for the soil, vegetation, animals, and humans. For this reason, the application of sludge to agricultural land is increasingly restricted.

\subsection{Legislation Context}

The new European fertilizers regulation published in March 2019 avoids the use of sewage sludge as feedstock for production of CE fertilizers. The sole fertilizing products obtainable from sludge, expected to be included by the new EU regulation are: struvite, phosphate salts, and the ashes after incineration process [9]. Despite the declared interest in recovery of organic matter and other nutrient elements from waste materials, the reuse of urban sludge in agriculture, is going to be more and more difficult in Europe, due to the strict limits on pollutants concentration, including metals, pharmaceuticals, and biological ones.

\subsection{Sewage sludge treatment}

At present, wastewater treatment companies can approach only two sludge disposal solutions: landfilling

\footnotetext{
* Corresponding author: david.chiaramonti@polito.it
} 
and incineration. For these reasons, industrial actors are trying to face the sludge disposal emergency in the quickest way: drying the material. SL drying is becoming the most common solution adopted by sludge producers to reduce volumes and, thus, the disposal costs. After drying process, the dry sludge is usually transported to landfills, or incinerators and, in few cases, mixed at low rate with compost.

\subsubsection{Drying and incineration}

Dryers available on the market can adopt different technologies (diathermic oil, belt drying, circulating bed drying, etc..). However, there is a threshold concerning the lowest energy consumption needed to evaporate 1 ton of water, which is $631 \mathrm{kWh} /$ ton of water to be removed (at atmospheric pressure). The below table reports energy consumption of two modern industrial dryers found on the market. The values are those declared by companies.

\begin{tabular}{lrl}
\hline Table 1. Energy consumption of two industrial dryers \\
\hline Diathermic Oil dryer [8] & & \\
\hline Thermal power & 2636 & $\mathrm{~kW}$ \\
Water evaporation capacity & 3,6 & $\mathrm{t} / \mathrm{h}$ \\
Outlet sludge humidity & $10 \%$ & \\
Th. Energy consumption & 741 & $\mathrm{kWh} / \mathrm{t} \mathrm{H} \mathrm{H}_{2} \mathrm{O}$ \\
\hline Screw dryer & & \\
\hline Thermal power & 477,0 & $\mathrm{~kW}$ \\
Water evaporation capacity & 0,6 & $\mathrm{t} / \mathrm{h}$ \\
Outlet sludge humidity & $10 \%$ & \\
Th. Energy consumption & $829 \mathrm{kWh} / \mathrm{t} \mathrm{H}_{2} \mathrm{O}$ \\
\hline
\end{tabular}

After drying, sludge is a stable, easy handling solid. However, the high amount of ashes $(20-40 \% \mathrm{db})$ and low calorific value (13-16 MJ/kg) make the dry sludge a low quality solid fuel. The incineration of a dry sludge having around $14 \mathrm{MJ} / \mathrm{kg}$, dried with diathermic Oil dryer of table 1 , would bring to a net energy production equal to $26 \%$ of the input calorific value, as more than $70 \%$ would be consumed for drying. Moreover, after the incineration process, ashes remain as a waste to dispose. For this reason, sludge incineration is still an expensive disposal system to be covered by sludge producers. This study aims to propose an economically, environmentally sustainable alternative technology to recover sludge as a valuable matter, with no residual streams.

\subsection{Structure of the proposed study}

The study was firstly based on assessing the performances of three different thermochemical routes for converting sludge into a carbon rich solid, and secondly on the application of an acid leaching process for reducing the solid ash content, extracting phosphorus and other critical raw materials. The work was thus distributed in two phases: (1) Assessing thermochemical treatment methods, including: slow pyrolysis of dry sludge in lab scale unit; hydrothermal Carbonization in $160 \mathrm{ml}$ autoclave; slow pyrolysis of HTC solid (SLH) in lab scale unit; (2) Slow Pyrolysis of dry sludge in $1 \mathrm{~kg} / \mathrm{h}$ pilot unit and chemical leaching of pyrolysed sludge.

\section{Technology state of the art}

\subsection{Slow pyrolysis}

Pyrolysis can be defined as a biomass thermo-chemical degradation process, taking place in absence of oxygen and at temperature above $185^{\circ} \mathrm{C}$. Slow pyrolysis is characterised by high temperatures (usually $>400^{\circ} \mathrm{C}$ ), low heating rate $\left(<20^{\circ} \mathrm{C} / \mathrm{min}\right)$ and long biomass retention time (more than 2 hours) [9]. In slow pyrolysis, sewage sludge is processed dry, with reduced moisture. The material is converted into pyro-gases, and a carbonrich solid. Ashes remain as inert part of the solid. The solid yield is usually around $25 \%$ of the input organic material, but since ashes don't participate to the reaction, high-ash materials result in higher solid mass yield. The pyro-gas are a compound of condensable hydrocarbons, and incondensable gases: $\mathrm{CO}, \mathrm{CO}_{2}, \mathrm{CH}_{4}$, $\mathrm{H}_{2}$. In industrial plants this stream is usually burnt to supply the energy required by the process. The amount of water (in form of vapour) in the pyro-gas depends on the humidity of the processed biomass. Biochar from sewage sludge is usually characterized by high ash content, which affects the calorific value, the porosity and thus the applicability of the char in many industrial processes.

\subsection{Hydrothermal carbonisation (HTC)}

Hydrothermal carbonization is defined as a wet pyrolysis. The process operates in absence, or lack of oxygen, at about $190-250^{\circ} \mathrm{C}$ and $18-40$ bar. In these subcritical conditions, water remains in liquid form. The HTC process is thus adopted for processing wet organic streams, with water content higher than $80 \% \mathrm{w} / \mathrm{w}$. The retention time of the wet biomass inside reactors usually goes from 0,5 to 4 hours [1]. In HTC plants, sewage sludge is treated after conventional centrifuge separation, thus with a water content up to $90 \%$. After the process, sludge is converted in a coal-water slurry, where organic particles are carbonized. At the end of the process, four streams are produced: a carbon-rich solid, named "hydrochar", obtained after drying the carbonized solid particles. This material is $90 \%$ dry, with higher volatility than biochar. A water phase, with high organic content, (COD $\sim 35.000 \mathrm{mg} / \mathrm{l}$ ), alkali metals, and ammonia $\left(\mathrm{NH}_{3}\right)$, almost equal in mass to the humidity of the processed material. The gas phase consists in mainly $\mathrm{CO}_{2}(99 \%), \mathrm{CO}$, and $\mathrm{H}_{2}$. The condensable vapours, usually around $2-3 \%$ of input material $[1,4,6]$.

\subsection{Chemical leaching}

Chemical Leaching is identified as that process where a solute contained in a substance is extracted from its 
carrier substance by way of solvent. The solvent, in the field of coals is usually an acid or base.

\section{Materials and Methods}

\subsection{Materials}

The material processed in this study is a dry sludge (SL) produced by a private company. SL was characterized in lab scale units. Below the characterisation results.

\begin{tabular}{lcc}
\hline \multicolumn{3}{l}{ Table 2. SL Proximate \& ultimate analysis (\% wb) } \\
\hline Parameter & Value & Standard \\
Humidity & 8.1 & UNI EN ISO 18134-2 \\
Ash & 19.0 & UNI EN ISO 1860-2 \\
Volatiles & 58.0 & UNI EN ISO 18123 \\
$\mathrm{C}$ & 39.5 & UNI EN ISO 16948 \\
$\mathrm{H}$ & 4.8 & UNI EN ISO 16948 \\
$\mathrm{N}$ & 6.9 & UNI EN ISO 16948 \\
$\mathrm{S}$ & 0.9 & UNI EN ISO 16994 \\
\hline
\end{tabular}

Table 3. SL elemental analysis (mg/kg db)

\begin{tabular}{lcc}
\hline Element & Value & Standard \\
$\mathrm{Al}_{2} \mathrm{O}_{3}$ & 28617 & UNI EN 14538 \\
$\mathrm{CaO}$ & 42336 & UNI EN 14538 \\
$\mathrm{FeO}$ & 648 & UNI EN 14538 \\
$\mathrm{~K}_{2} \mathrm{O}$ & 8749 & UNI EN 14538 \\
$\mathrm{MgO}$ & 4285 & UNI EN 14538 \\
$\mathrm{MnO}$ & 307 & UNI EN 14538 \\
$\mathrm{Na}_{2} \mathrm{O}$ & 23183 & UNI EN 14538 \\
$\mathrm{P}_{2} \mathrm{O}_{5}$ & 54226 & UNI EN 14538 \\
$\mathrm{SiO}_{2}$ & 83979 & UNI EN 14538 \\
$\mathrm{TiO}_{2}$ & 9788 & UNI EN 14538 \\
$\mathrm{ZnO}$ & 116 & UNI EN 14538 \\
\hline
\end{tabular}

\subsection{Slow pyrolysis}

The slow pyrolysis process was performed using two different units. In the first phase of the study, slow pyrolysis was performed in a LECO TGA 701 thermogravimetric analyser, heating at a $20^{\circ} \mathrm{C} \mathrm{min}^{-1}$ and 3.51 $\mathrm{min}^{-1}$ nitrogen flow. This methodology has been adopted for pyrolysing, at the same conditions, both raw sludge (SL), and the solid (SLH) produced after processing SL in the HTC unit. Solid products obtained from slow pyrolysis of SL and SLH are named: SLB $_{\mathrm{TGA}}, \mathrm{SLHB}_{\mathrm{TGA}}$. After the comparison of three solutions investigated in phase 1, slow pyrolysis of dry sewage sludge was performed in a pilot unit designed by RE-CORD. The experimental apparatus utilized consists in a tubular stainless steel reactor and a double counter-flow water condensing system, integrated with a bubbler for gas cleaning installed before gas outlet filters. The heating of the reactor is achieved by means of electric heaters and inert atmosphere is ensured by a flow of $\mathrm{N}_{2}$. The target of this last experimental activity was to produce higher amounts of biochar $\left(\mathrm{SLB}_{\mathrm{py}}\right)$ in almost real ambient, to be used in leaching tests of phase 2 .

\subsubsection{Slow pyrolysis experimental methodology}

As regards of the slow pyrolysis tests performed in TGA, 260,7 grams of SL were charged in the machinery crucibles. The machinery was set with a heating rate of $20^{\circ} \mathrm{C} / \mathrm{min}$, with set process temperature at $450^{\circ} \mathrm{C}$ and 2 hours of retention time. The second experimental activity was performed in pilot plant and consisted in charging the unit with $604 \mathrm{~g}$ of dry sludge and operated in fixed bed methodology. The machinery was heated until reaching the same operating temperature set for TGA experiments: 2 hours, $450^{\circ} \mathrm{C}$.

\subsection{HTC Autoclave}

The hydrothermal carbonization experiments were conducted in a custom-made autoclave. The reactor consists in a $160 \mathrm{ml}$ net volume AISI 316 stirred autoclave. It is equipped with $\mathrm{T}$ sensors, a pressure transducer and a pressure relief valve for safety depressurization. The reactor is connected to an argon cylinder for pressurization. Heating is performed with external electric heater.

\subsubsection{HTC experimental methodology}

The HTC process experiment consisted in mixing $20 \mathrm{~g}$ of SL at $8,1 \%$ moisture and $80 \mathrm{ml}$ of demineralized water, producing $100 \mathrm{~g}$ of solution at $18.6 \%$ of dry matter in the autoclave. The autoclave was weighted before the process and pre-pressurized at 10 bars with Argon. After pressurization, process temperature was set at $205^{\circ} \mathrm{C}$, with stirrer agitation. The autoclave was heated at $3,3^{\circ} \mathrm{C} / \mathrm{min}$, from room temperature until set temperature $\left(205^{\circ} \mathrm{C}\right)$ and then kept for 2 hours at process set conditions. After 2 hours, cooling process started until internal temperature was below $40^{\circ} \mathrm{C}$. After cooling, the autoclave was depressurized at atmospheric pressure. The depressurized autoclave was weighted in order to estimate the mass of produced gases. As last step, autoclave was opened and HTC slurry was separated in acqueous and solid phase using a vacuum funnel filtering unit. Separated solid (SLH) was then dryed at $105^{\circ} \mathrm{C}$ for 24 hours and then weighted for assessing the dry mass balance obtained from the process. This process has been repeated twice at the same conditions.

\subsection{Chemical leaching}

The chemical leachin experiments consisted in upgrading the pyrolysis solid product $\left(\mathrm{SLB}_{\mathrm{py}}\right)$, extracting phosphates and other critical materials, thus reducing its ash content and thus increasing its properties as biocoal. 


\subsubsection{Methodology}

$\mathrm{SLB}_{\text {py }}$ samples were mixed with demineralized water at different concentration: $10 \% \mathrm{w} / \mathrm{w}$, and $5 \% \mathrm{w} / \mathrm{w}$. The so prepared char-water solution was acidified using two different acid reagents: $\mathrm{HNO}_{3}$, and $\mathrm{H}_{2} \mathrm{SO}_{4}$, for 3 hours, at room temperature, in stirred glass vessels. The reagents concentration was established starting from previous experiences $[6,7,8]$ therefore, two different concentrations have been tested for both reagents: $50 \%$, and $60 \% \mathrm{w} / \mathrm{w}$ of processed $\mathrm{SLB}_{\mathrm{py}}$. After leaching, charliquid solution was separated using a buchner funnel with no-ash cellulosic paper filters, installed over a suction glass bottle with a vacuum pump. Liquid fraction was collected and analysed in ICP, solid fraction was dried 24 hours at $105^{\circ} \mathrm{C}$ before being analysed in TGA and CHN instruments

\section{Results of experiments}

\subsection{HTC of wet sludge}

The solid mass yield of the HTC process was calculated on dry basis as the ratio between the raw sludge mass on dry basis, and the weighted mass of HTC solid product after 24 hours drying at $105^{\circ} \mathrm{C}$. Mass yield for two HTC trials is reported in Table 4.

Table 4. Mass yield of HTC autoclave trials

\begin{tabular}{lccc}
\hline Sample & SL & SLH & \% m. yield \\
\hline Trial 1 & 18.36 & 8.36 & 0.455 \\
Trial 2 & 18.36 & 8.50 & 0.463 \\
\hline
\end{tabular}

The study focused on solid fraction, which was analysed to determine ash content and characteristics.

Table 5. Proximate \& ultimate analysis of SLH (\% db)

\begin{tabular}{lcc}
\hline Parameter & Value & Standard \\
\hline Ash & 44.36 & UNI EN ISO 1860-2 \\
Volatiles & 63.1 & UNI EN ISO 18123 \\
$\mathrm{C}$ & 42.16 & UNI EN ISO 16948 \\
$\mathrm{H}$ & 3.8 & UNI EN ISO 16948 \\
$\mathrm{N}$ & 3.1 & UNI EN ISO 16948 \\
$\mathrm{S}$ & 1.07 & UNI EN ISO 16994 \\
\hline
\end{tabular}

As visible, $\mathrm{C}$ content almost didn't increase compared to input material due to the increase of ash content. SLH sample showed high hydrogen and volatile content, typical of hydrothermal carbonisation treatment process

\begin{tabular}{lcc}
\hline \multicolumn{2}{l}{ Table 6 Elemental analysis of SLH $(\mathbf{m g} / \mathbf{k g}(\mathbf{d b}))$} \\
\hline Parameter & Value & Standard \\
\hline $\mathrm{Al}_{2} \mathrm{O}_{3}$ & 8689 & DIN EN $15309: 2007$ \\
$\mathrm{CaO}$ & 208600 & DIN EN 15309:2008 \\
$\mathrm{FeO}$ & 3474 & DIN EN 15309:2013 \\
$\mathrm{K}_{2} \mathrm{O}$ & 5302 & DIN EN $15309: 2014$ \\
\hline
\end{tabular}

\begin{tabular}{lcl}
\hline $\mathrm{MgO}$ & 9000 & DIN EN $15309: 2015$ \\
$\mathrm{MnO}$ & 2195 & DIN EN $15309: 2016$ \\
$\mathrm{Na}_{2} \mathrm{O}$ & 6200 & DIN EN $15309: 2018$ \\
$\mathrm{P}_{2} \mathrm{O}_{5}$ & 150245 & DIN EN $15309: 2020$ \\
$\mathrm{SiO}_{2}$ & 31071 & DIN EN $15309: 2022$ \\
$\mathrm{TiO}_{2}$ & 58765 & DIN EN $15309: 2023$ \\
$\mathrm{ZnO}$ & 498 & DIN EN $15309: 2024$ \\
\hline
\end{tabular}

The concentration of three elements in SLH resulted much lower than input material: $\mathrm{Al}, \mathrm{Na}, \mathrm{K}$, which probably passed from solid to water [1]. However, this reduction didn't result in a strong reduction of ashes, probably due to the loss of oxygen, and part of organic carbon in the water phase.

\subsection{Slow pyrolysis of dry sludge}

Slow pyrolysis process was performed in two instruments: TGA LECO 701, and a $1 \mathrm{~kg} / \mathrm{h}$ slow pyrolysis pilot unit. Mass balance of performed trials is reported below.

Table 7. Mass yield of TGA and Pyro Unit trials

\begin{tabular}{lccc}
\hline Test & Dry SL & Solid output & \% m. yield \\
TGA LECO & 260,6 & 117,1 & $44.9 \%$ \\
Pyro Unit & 604 & 325 & $53.8 \%$ \\
\hline
\end{tabular}

Trial performed using pilot unit resulted in higher mass yield and, thus, lower ash content. Composition of $\mathrm{SLB}_{\mathrm{TGA}}$ and $\mathrm{SLB}_{\mathrm{py}}$, is reported below.

\begin{tabular}{lccc}
\hline $\begin{array}{l}\text { Table 8. Proximate\& } \\
\text { SLB }\end{array}$ ultimate analysis of SLB $_{\text {py }}$ and \\
\multicolumn{1}{l}{ (\%) } \\
\hline Parameter. & SLB $_{\text {py }}$ & SLB $_{\text {TGA }}$ & Standard \\
Moisture & 2.8 & 2.3 & UNI EN ISO 18134-2 \\
Ash & 40.4 & 44.3 & UNI EN ISO 18134-2 \\
Volatiles & 21.8 & 20.9 & UNI EN ISO 1860-2 \\
C & 42.0 & 41.0 & UNI EN ISO 18123 \\
H & 2.0 & 1.7 & UNI EN ISO 16948 \\
N & 5.3 & 5.4 & UNI EN ISO 16948 \\
S & 1.1 & 1.2 & UNI EN ISO 16948 \\
\hline
\end{tabular}

As a consequence, also concentration of most inorganic elements is lower in $\mathrm{SLB}_{\mathrm{py}}$ compared to SLB $\mathrm{TGA}$

Table 9 Elemental analysis of SLBPy and SLB TGA $(\mathrm{mg} / \mathrm{kg}$ (db))

\begin{tabular}{cccc}
\hline Parameter & SLB $_{\text {py }}$ & SLB $_{\mathrm{TGA}}$ & Standard \\
\hline $\mathrm{Al}_{2} \mathrm{O}_{3}$ & 49995 & 95816 & UNI EN ISO 16994 \\
$\mathrm{CaO}$ & 88400 & 107241 & DIN EN $15309: 2007$ \\
$\mathrm{FeO}$ & 3176 & 2028 & DIN EN $15309: 2012$ \\
$\mathrm{~K}_{2} \mathrm{O}$ & 20316 & 22656 & DIN EN $15309: 2013$ \\
$\mathrm{MgO}$ & 9025 & 9047 & DIN EN 15309:2014 \\
$\mathrm{MnO}$ & 258 & 634 & DIN EN $15309: 2015$ \\
$\mathrm{Na}_{2} \mathrm{O}$ & 53544 & 59900 & DIN EN 15309:2017 \\
$\mathrm{P}_{2} \mathrm{O}_{5}$ & 84073 & 105616 & DIN EN 15309:2019 \\
$\mathrm{SiO}_{2}$ & 17292 & 32057 & DIN EN $15309: 2021$ \\
\hline
\end{tabular}




\begin{tabular}{cccc}
\hline $\mathrm{TiO}_{2}$ & 23326 & 25232 & DIN EN 15309:2022 \\
$\mathrm{ZnO}$ & 265 & 232 & DIN EN 15309:2023 \\
\hline
\end{tabular}

\subsection{Slow pyrolysis of hydrochar}

The objective of this step was to upgrade the hydrochar (SLH) from a high volatile, low grade biocoal, to a low volatile, high grade material. To this end, pyrolysis of SLH was performed using the same instrument TGA LECO 701. The process was carried out at same conditions adopted for $\mathrm{SLBH}_{\text {tga }}$ production : $450^{\circ} \mathrm{C}, 20^{\circ} \mathrm{C} / \mathrm{min}, 2$ hours. The mass yield, calculated as the ratio between input SLH in TGA instrument, and output solid product, was around $70 \% \mathrm{db}$.

\section{Table 10. Mass yield of hydrochar pyrolysis trials}

\begin{tabular}{lccc}
\hline Test & SLH $(\mathbf{g})$ & SLHB $_{\text {TGA }}(\mathbf{g})$ & Mass yield \\
\hline TGA LECO 1 & 1.87 & 1.29 & $69.3 \%$ \\
TGA LECO 2 & 2.22 & 1.55 & $69.9 \%$ \\
\hline
\end{tabular}

The obtained char started from a high ash content, therefore, the composition was the following:

Table 11. Proximate\& ultimate analysis of $\operatorname{SLBH}_{\mathrm{TGA}}(\% \mathrm{db})$

\begin{tabular}{lcc}
\hline Parameter & SLBH $_{\text {TGA }}$ & Standard \\
\hline Ash & 61.34 & UNI EN ISO 18134-2 \\
Volatiles & 14.5 & UNI EN ISO 1860-2 \\
$\mathrm{C}$ & 34.1 & UNI EN ISO 18123 \\
$\mathrm{H}$ & 1 & UNI EN ISO 16948 \\
$\mathrm{N}$ & 2.1 & UNI EN ISO 16948 \\
$\mathrm{S}$ & 0.84 & UNI EN ISO 16948 \\
\hline
\end{tabular}

Table 12. Elemental analysis of SLBH ${ }_{\mathrm{TGA}}(\mathrm{mg} / \mathrm{kg})$

\begin{tabular}{lcc}
\hline Parameter & SLBH $_{\text {TGA }}$ & Standard \\
\hline $\mathrm{Al}_{2} \mathrm{O}_{3}$ & 43822 & UNI EN ISO 16994 \\
$\mathrm{CaO}$ & 266000 & DIN EN $15309: 2007$ \\
$\mathrm{FeO}$ & 4504 & DIN EN $15309: 2012$ \\
$\mathrm{~K}_{2} \mathrm{O}$ & 5785 & DIN EN $15309: 2013$ \\
$\mathrm{MgO}$ & 5333 & DIN EN $15309: 2014$ \\
$\mathrm{MnO}$ & 2194 & DIN EN $15309: 2015$ \\
$\mathrm{Na}_{2} \mathrm{O}$ & 270 & DIN EN $15309: 2017$ \\
$\mathrm{P}_{2} \mathrm{O}_{5}$ & 144290 & DIN EN $15309: 2019$ \\
$\mathrm{SiO}_{2}$ & 29357 & DIN EN 15309:2021 \\
$\mathrm{TiO}_{2}$ & 55760 & DIN EN 15309:2022 \\
$\mathrm{ZnO}$ & 747 & DIN EN 15309:2023 \\
\hline
\end{tabular}

As expected SLBH show a very low volatile content and low hydrogen content, with high ash concentration.

\subsection{Mass balance and energy consumption}

The energy consumption assessment was based on experiences and on data from sludge drying plants [8], HTC, and slow pyrolysis $[4,5,9]$. The energy consumption comparison between drying and HTC plants was calculated considering a sludge input of
$5000 \mathrm{~kg}$, at $20 \%$ dry matter. Electricity consumption has not been included in the calculation. Pyrolysis has been considered as energy self-sufficient.

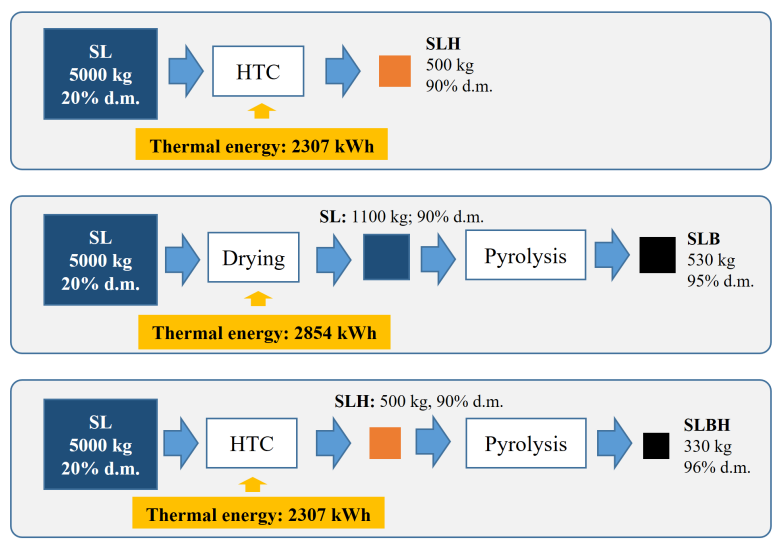

Figure 1. Mass balance and energy consumption of thermochemical routes processes

HTC results in a low energy consumption and, more important, in a strong reduction of solid matter output. However, drying eliminates water in form of vapour, while the water phase of HTC process represents a high volume of material to handle with relevant costs and electricity consumption. Additionally, the study showed strong losses of matter in HTC water phase during the process with consequent high ash content in SLH sample. Moreover, hydrochar pyrolysis performed to reduce volatility of the material brought to produce a carbonaceous solid (SLBH) with very high ash concentration $(>60 \%)$. For this reason, SLB obtained from direct low pyrolysis of SL was considered the most reliable material on which performing chemical upgrading and critical raw materials extraction.

\section{Extraction of Critical Raw Materials}

As visible from Table $8, \mathrm{SLB}_{\mathrm{py}}$ presented a high concentration of interesting inorganic elements. In particular: Ti, Na, Fe, Mg, K, P, Si, Al, Ca. Five of these elements: $\mathrm{Fe}, \mathrm{Mg}, \mathrm{P}, \mathrm{Ca}, \mathrm{K}$, are of great interest for agriculture. Other two elements: $\mathrm{Si}$, and $\mathrm{Al}$, represents high value elements for different industry sectors. The leaching activity was firstly focused on leaching phosphate, as it represents a high value critical element, of with scarce availability. 


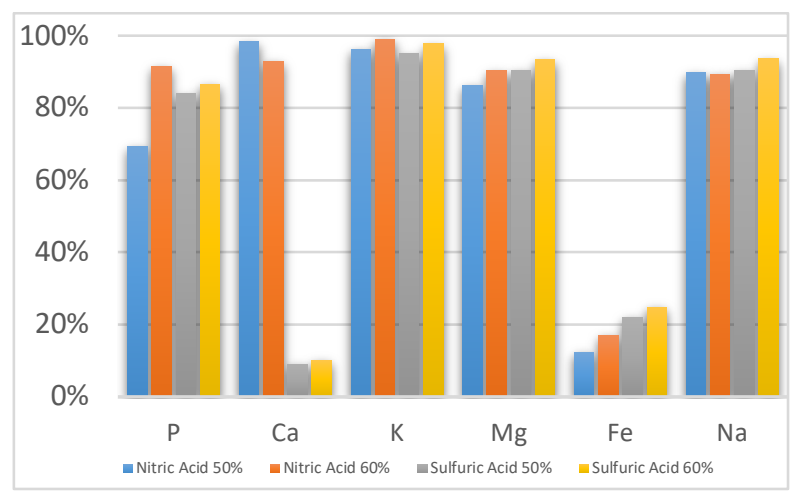

Figure 2. Extraction efficiency of inert elements in $\mathrm{SLB}_{\mathrm{py}}$

The results of the leaching investigation are reported in Figure 2. shows that both $\mathrm{H}_{2} \mathrm{SO}_{4}$ and $\mathrm{HNO}_{3}$ ensured a high $\mathrm{P}$ extraction efficiency. Also other important elements: $\mathrm{K}$ and $\mathrm{Mg}$ were extracted with high efficiency. Main different between two reagents was that $\mathrm{H}_{2} \mathrm{SO}_{4}$ removed undesired elements like $\mathrm{Zn}$ and $\mathrm{Al}$ in high concentration, while almost not extracting Calcium, which is strongly influencing the ash content of the char.

\subsection{Single stage leaching}

For achieving high reduction ashes in single stage leaching, $\mathrm{HNO}_{3}$ was considered a better solution for ensuring high value of the extracted liquid and, at the same time, a strong ash content reduction in biochar.

\subsection{Ash reduction in char}

A char sample has been produced processing $10 \mathrm{~g}$ of SLB in $90 \mathrm{ml}$ demineralized water, adding $6 \mathrm{~g}$ HNO3 (azeotrope 68\%), thus at $60 \% \mathrm{w} / \mathrm{w}$ on char total mass. The table shows that ash content has been reduced from $41,6 \% \mathrm{db}$ to $16,7 \% \mathrm{db}$

Table 13.SLB_L proxymate and ultimate analysis (\% $\mathrm{db})$

\begin{tabular}{ccccccc}
\hline Sample & C & H & N & S & Volatiles & Ash \\
\hline SLB $_{\text {py }}$ L & 58.8 & 3.1 & 8.5 & 0.3 & 22,2 & 16,7 \\
\hline
\end{tabular}

The obtained biochar quality has also been assessed considering main identification parameters used in Van Krevelen diagram to classify the coal types: Atomic $\mathrm{H} / \mathrm{C}$, atomic $\mathrm{O} / \mathrm{C}$.

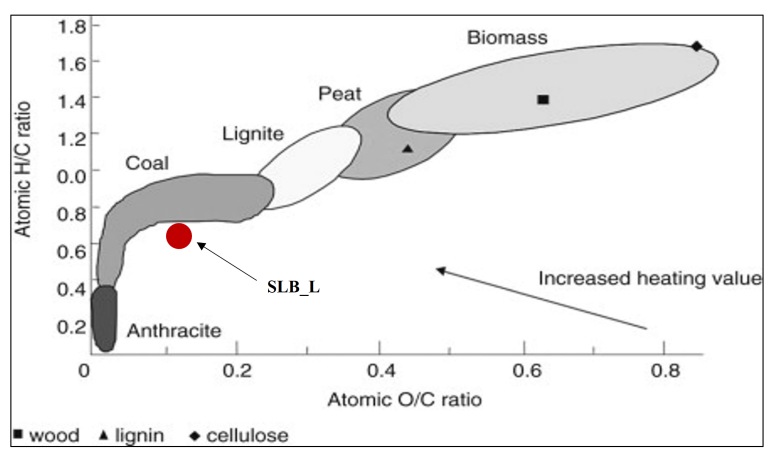

Figure 3. Van Kreleven coal classification chart

According to the results of Fig. 3, the coal is fully complying with thermal coal specifications

\subsection{Liquid composition}

The liquid stream resulting from leaching process showed a high extraction efficiency of most interesting elements.

Table 14. Element analysis of leached liquid

\begin{tabular}{lcc}
\hline \multicolumn{1}{c}{ Element } & $\mathbf{m g} / \mathbf{l}$ & Extraction efficiency \\
\hline $\mathrm{P}$ & 1820 & $92 \%$ \\
$\mathrm{Ca}$ & 6410 & $93 \%$ \\
$\mathrm{~K}$ & 920 & $99 \%$ \\
$\mathrm{Mg}$ & 530 & $90 \%$ \\
$\mathrm{Fe}$ & 46 & $17 \%$ \\
$\mathrm{Zn}$ & 12 & $50 \%$ \\
$\mathrm{Al}$ & 1210 & $84 \%$ \\
$\mathrm{Na}$ & 1936 & $89 \%$ \\
\hline
\end{tabular}

This liquid is a high value co-product of interest for fertilizing sector

\section{Conclusion and follow up}

Thermochemical treatment experiments showed that HTC is less energy demanding than drying. At the same time, two bottlenecks have been identified concerning HTC: HTC plants CAPEX is higher than industrial driers, and water phase must be treated, with consequent additional costs. On the other side, water phase high COD can be valorised by anaerobic digestion for biogas production, with benefits on process energy balance and sustainability. Moreover, if HTC is applicated as as pretreatment before pyrolysis, it must be considered that HTC process reduces solid material of around 50\% compared to drying process, halving the required slow pyrolysis plant treatment capacity. Despite some ash elements are removed from solid after HTC, the high ash content of pyrolysed hydrochar (SLBH) is high. This can affect the impact of the leaching process on the achievement of a sufficiently low ash content $(<20 \%)$. Integration of SL slow pyrolysis and chemical leaching demonstrated to be a sustainable system, of potential interest for industry sector, with good performances and 
an effective recovery of three important critical raw materials: Coking coal, Phosphorus, Magnesium.

\subsection{Follow up}

The ongoing activity of this study is approaching a further optimization of the process, both in terms of thermochemical treatment, and leaching activity. Further trials are being performed to process sludge in HTC and Slow Pyrolysis at lower temperature and to assess HTC water biogas production, to improve the energy balance and ensure a better quality of the final pyrolysed hydrochar. Additionally, a two stage leaching activity is ongoing, using $\mathrm{H}_{2} \mathrm{SO}_{4}$ as acid reagent, in the first step, and a second mineral base for extracting all those mentioned materials, plus Silicon. With this solution, 4 critical raw materials can be extracted, with a further reduction of biochar ash content, with direct impact on the whole process economic and environmental benefits.

\section{References}

[1] L. Doyle, a. Salimbeni, et al. 2016, "Industrial scale hydrothermal carbonization: new applications for wet biomass waste", ISBN: 978-3-00-052950-4

[2] Tasca AL, Puccini M, Gori R, Corsi I, Galletti AMR, Vitolo S. Hydrothermal carbonization of sewage sludge: A critical analysis of process severity, hydrochar properties and environmental implications. Waste Manag 2019;93:1-13. https://doi.org/10.1016/j.wasman.2019.05.027

[3] Lucian M, Fiori L. Hydrothermal carbonization of waste biomass: Process design, modeling, energy efficiency and cost analysis. Energies 2017;10. https://doi.org/10.3390/en10020211.

[4] Organic waste streams upgrading for gasification process optimization. A. Salimbeni, 2019, "Substitute natural gas from waste: technical assessment and industrial applications of biochemical and thermochemical processes". Isbn: 978-0-12-815554-7.

[5] Dhawan H, Sharma DK. Advances in the chemical leaching (inorgano-leaching), bio-leaching and desulphurisation of coals. Int J Coal Sci Technol 2019;6:169-83. https://doi.org/10.1007/s40789019-0253-6.

[6] Ehrnström MS. Recovery of Phosphorus from HTC Converted Municipal Sewage Sludge. MS Thesis 2016.

[7] Borja Oliver-Tomas, Martin Hitzl, Mikołaj Owsianiak, Michael Renz. Evaluation of hydrothermal carbonization in urban mining for the recovery of phosphorus from the organic fraction of municipal solid waste, Resources, Conservation and Recycling, Volume 147, 2019, Pages 111-118, ISSN 0921-3449. https://doi.org/10.1016/j.resconrec.2019.04.023.

[8] Impianto di essicamento termico, Gruppo SMAT
[9] Huygens, D., Saveyn, H., Tonini, D., Eder, P. and Delgado Sancho, L., Technical proposals for selected new fertilising materials under the Fertilising Products Regulation (Regulation (EU) 2019/1009), EUR 29841 EN, Publications Office of the European Union, Luxembourg, 2019, ISBN 978-92-76-09888-1. 